\title{
POROSITY OF THE FINE FRACTIONS OF FINNISH TILLS
}

\author{
PERTTI NIEMINEN and AARRE KELLOMÄKI
}

\begin{abstract}
NIEMINEN, PERTTI and KELLOMÄKI, AARRE, 1984: Porosity of the fine fractions of Finnish tills. Bull. Geol. Soc. Finland 56, Part 1-2, 221-226.

Pore properties of 64 soil samples were studied with mercury porosimetry. The samples were typical Finnish tills and related materials. All samples show porosimetry curves with strong mercury penetration around the pore diameters of $6 \mu \mathrm{m}$. This is interpreted to correspond to true pores of that size. The porosity percentage of the samples found by $\mathrm{Hg}$ porosimetry is about $50 \%$ of the bulk volume. In addition, there is another ca. $10 \%$ of the volume in the pores with smaller than $6 \mathrm{~nm}$ diameters which are inaccessible to mercury. Specific surface areas computed from the $\mathrm{Hg}$ porosimetry are of reasonable sizes, about one half of the nitrogen BET areas. For 33 samples the mesopore distributions were computed from water adsorption data. These results roughly agree with the results of $\mathrm{Hg}$ porosimetry, but the adsorption method does not yield information about large pores.
\end{abstract}

Key words: till, porosity

Pertti Nieminen: Laboratory of Engineering Geology, Tampere University of Technology, P.O. Box 527, SF-33101 Tampere 10, Finland.

Aarre Kellomäki: Department of Biomedical Sciences, University of Tampere, P.O. Box 607, SF-33101 Tampere 10, Finland.

\section{Introduction}

Many physical and chemical properties of powdered materials, e.g. the cation exchange capacity of soils and their ability to retain water, depend on their large specific surface areas. Surface areas even as large as several hundred thousand square meters per kilogram are possible only because such materials are porous: They contain void volume between and inside the particles (Gregg and Sing 1982). The porosity also affects the dynamic properties of powdered materials, such as the flow of gases or liquids through them. Thus, the capillarity of soils is a direct consequence from their porosity and other microtexture.

The porosity of materials was first studied applying gas adsorption, especially the adsorption of nitrogen at low temperatures, or methods based on gas permeability. A great advancement in this field was the employment of mercury porosimetry after the second world was (van Brakel et al. 1981). During the last decade porosimeters have been developed into practical and precise instruments which are suitable for ordinary laboratories, too.

In this work pore properties of the fine fractions of Finnish tills were studied by mercury 

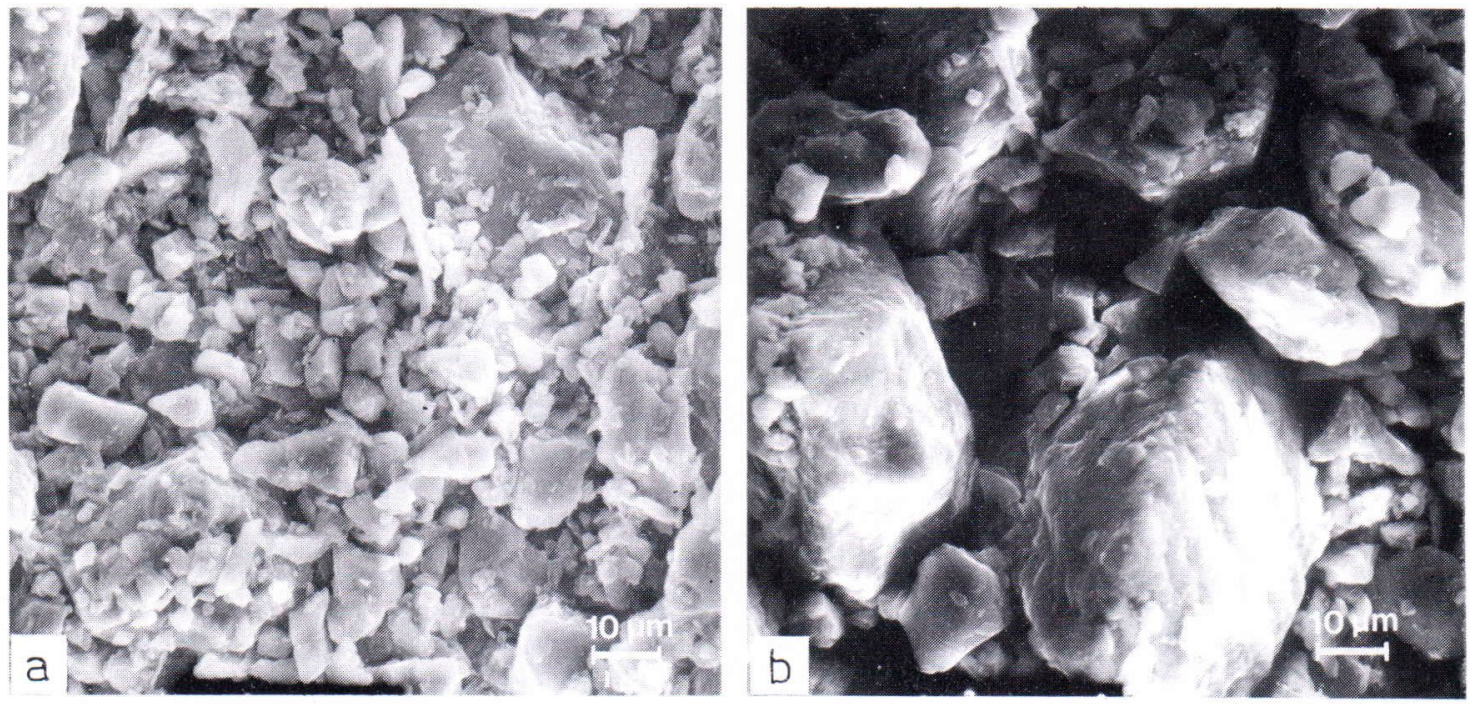

Fig. 1. SEM photographs of two sandy tills. The clay content $(<2 \mu \mathrm{m})$ of sample a) is $4 \%$ and the nitrogen BET area $3,000 \mathrm{~m}^{2} / \mathrm{kg}$. The corresponding parameters of sample b) are $1 \%$ and $4,500 \mathrm{~m}^{2} / \mathrm{kg}$.

porosimetry. For some samples the mesopore distributions were also computed from water adsorption data. This study is part of a more extensive research project in which properties of Finnish tills are investigated.

\section{Materials and methods}

This study comprised 64 soil samples: 48 sandy tills, 6 silty tills, and 10 weathering till materials. The samples represent typical Finnish ablation and lodgement tills. The materials were used without any purification. Thus, any humus or ferric hydroxide sols in them were preserved. In order to get more homogenous samples the materials were sieved, and fine fractions under $74 \mu \mathrm{m}$, amounting to 13 to $68 \%$ of the total mass of the raw materials, were used for the measurements. Before the experiments the samples were dried at $105^{\circ} \mathrm{C}$. Typical structures of the samples are shown in Fig. 1.

The mercury porosimetric measurements were done with a Micromeritics Pore Sizer 9300 instrument according to the manufacturer's in- structions: The sample is put into a tared penetrometer tube and weighed. The tube is evacuated and filled with $\mathrm{Hg}$ at the minimum pressure (about $3 \mathrm{~Pa}$ ). Now the pores with diameters larger than $300 \mu \mathrm{m}$ are filled and the bulk volume of the sample is obtained. When the pressure is gradually increased, the $\mathrm{Hg}$ penetrates into smaller and smaller capillaries. The filled pore volume can be computed from the capacitance of the penetrometer. At reaching the atmospheric pressure the pores just being filled are $12 \mu \mathrm{m}$ in diameter (see Fig. 1). The penetrometer is now detached, weighed, and inserted in the high pressure site where hydraulic pressure is applied. With some tens of increments the pressure is gradually raised to the maximum of about $200 \mathrm{MPa}$ (30,000 Psia) and the pores down to about $6 \mathrm{~nm}$ are filled. On returning to the atmospheric pressure a hysteresis loop can be observed.

In helium pycnometry a Micromeritics Model 1302 instrument was used. The BET areas were determined with a Micromeritics Surface Area Analyzer MIC-2200. Scanning electron micrographs were taken with a JEOL JSM3 SEM in- 
Table 1. Pore properties of till samples expressed as means and their standard deviations. The number of samples is 25 to 64 in various cases.

Bulk density of loosely packed powder

Apparent density found by mercury porosimetry

True density found by helium pycnometry

Porosity percentage found by mercury porosimetry

Porosity percentage found by water adsorption

Porosity percentage found by helium pycnometry

Median pore diameter in mercury porosimetry

Median pore diameter in water adsorption

Specific surface area found by mercury porosimetry

Specific surface area found by water adsorption (calculation extended to R.H. of $43 \%$ )

BET area found by nitrogen adsorption

$$
\begin{aligned}
& 1.12 \pm 0.21 \mathrm{~kg} \mathrm{dm}^{-3} \\
& 2.10 \pm 0.32 \mathrm{~kg} \mathrm{dm}^{-3} \\
& 2.80 \pm 0.09 \mathrm{~kg} \mathrm{dm}^{-3} \\
& 47 \pm 8 \% \\
& 2.3 \pm 1.7 \% \\
& 61 \pm 6 \% \\
& 5.9 \pm 2.8 \mu \mathrm{m}^{-3} \\
& 22 \pm 12 \mathrm{~nm}^{\circ} \\
& 4100 \pm 2700 \mathrm{~m}^{2} \mathrm{~kg}^{-1} \\
& 8100 \pm 5400 \mathrm{~m}^{2} \mathrm{~kg}^{-1} \\
& 5300 \pm 3600 \mathrm{~m}^{2} \mathrm{~kg}^{-1} \\
& 51
\end{aligned}
$$

strument which offers a possibility for microanalysis, too. The experimental details of the measurement of water adsorption are described elsewhere (Nieminen and Kellomäki 1982 a).

\section{Results and discussion}

The original detailed data have been published in the report series of Tampere University of Technology, Department of Civil Engineering (Nieminen and Kellomäki 1982 b). As a general summary of the results some typical properties of the samples are listed in Table 1. The most important features of the results, and the conclusions drawn from them, are discussed in the following.

\section{Mercury porosimetry}

Figure 2 shows typical examples of the porosimetry results, the curves for the samples of Fig. 1. They have been plotted against the pore diameters $\mathrm{D}$ on a semilogarithmic scale by marking the maximum value of each quantity with $100 \%$. The diameter D of the pores just filled at pressure $\mathrm{p}$ can be computed according to the cylinder tube model (Gregg and Sing 1982; Lowell 1979) from equation

$$
\mathrm{D}=-\frac{4 \gamma \cos \theta}{\mathrm{p}}
$$

Here $\gamma$ is the surface tension of mercury (484 $\mathrm{mN} \mathrm{m}^{-1}$ ) and $\theta$ the contact angle between mercury and the sample; a value of $130^{\circ}$ used in the calculations. The cumulative pore volumes $\mathrm{V}$ were computed from the established capacitances
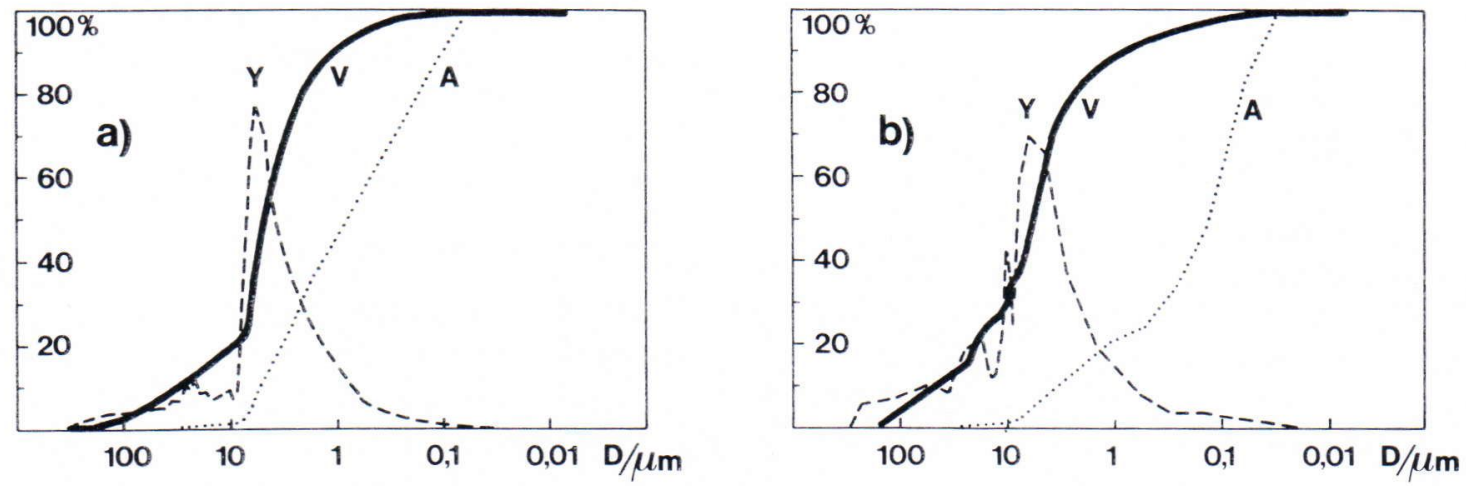

Fig. 2. Porosity curves of samples a) and b): V is cumulative pore volume, Y pore volume distribution, and A cumulative surface area. The following values can be derived from the results of a) and b), respectively: Median pore diameter $4.8 \mu \mathrm{m}$ and $6.0 \mu \mathrm{m}$, porosity $47.6 \%$ and $31.5 \%$, specific surface area $930 \mathrm{~m}^{2} / \mathrm{kg}$ and $1,190 \mathrm{~m}^{2} / \mathrm{kg}$. 
using the parameters given by the instrument manufacturer. At higher pressures the capacitances were corrected for immaterial changes due to the compressibility and warming of $\mathrm{Hg}$; the corrections were obtained from blank runs with penetrometers filled only with $\mathrm{Hg}$. The pore volume distribution was described with a function:

$$
Y=\frac{d V}{d(\lg D)}
$$

In order to smooth the curve it was plotted as the mean of three successive points.

All the porosity curves of the till samples are alike. The initial $\mathrm{Hg}$ penetration is due to the void volume between the particles. The true pores must have diameters distinctly smaller than the particle sizes ( $<<74 \mu \mathrm{m}$ ). In all our samples strong $\mathrm{Hg}$ penetration was found in the region of $\mathrm{D}=1$ to $20 \mu \mathrm{m}$, characterized by the median pore diameter $\mathrm{D}_{\mathrm{m}}$ when $50 \%$ of the mercury-accessible pore volume is filled (Fig. 3). The $D_{m}$ is not correlated with the particle size distribution curves (sieve curves) of the

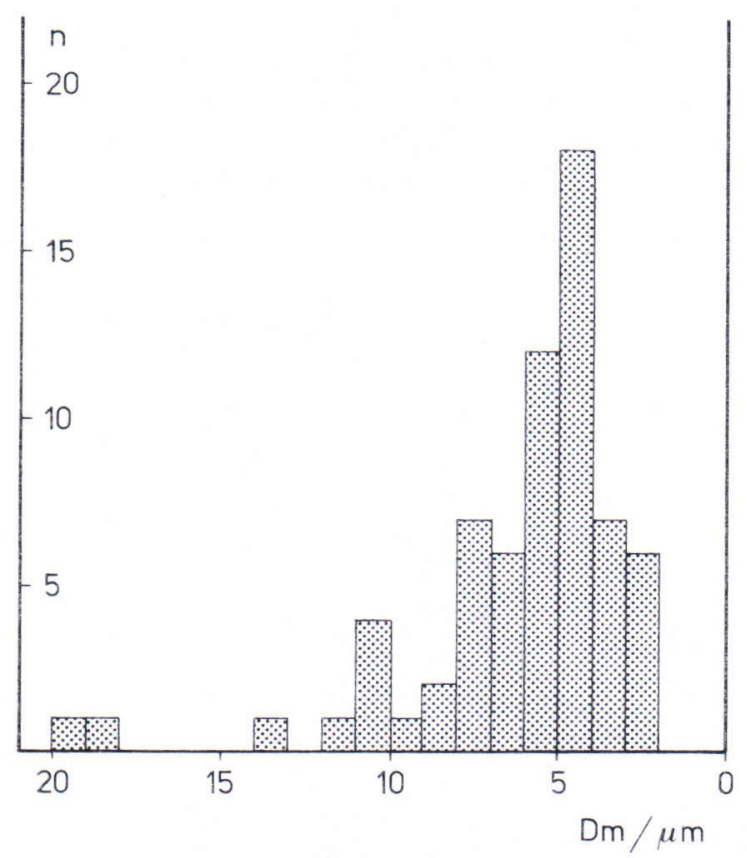

Fig. 3. Distribution of median pore diameters of till samples. samples which proves that a significant part of the pore volume in this region comes from true pores. Indirect evidence from the large specific surface areas also speaks for this conclusion. The pores are already in the original particles, but if the clay content $(<2 \mu \mathrm{m})$ is high, e.g. more than $5 \%$, part of the pores may have been formed in the drying process by sintering particles together. Cold drying could preserve the original texture of the samples in such cases.

At the maximum pressure $\mathrm{Hg}$ can penetrate into pores with diameters of about $6 \mathrm{~nm}$. In a typical case the established pore volume is then one half of the geometric bulk volume. According to the results of helium pycnometry one can, however, conclude that about a quarter of the total pore volume is in the even smaller mesopores and micropores.

The cumulative surface areas were computed with the equation (Rootare and Prenzlow 1967)

$$
A=-\frac{1}{\gamma \cos \theta} \int_{0}^{V} p d V,
$$

where the symbols have the same meanings as before. The porosimeter method for determining specific areas is quite practical and the results are of reasonable size. In most cases they are 30 to $60 \%$ of the BET areas obtained by nitrogen adsorption, but the difference can be explained by the fact that nitrogen can penetrate into smaller capillaries than mercury at the applied pressure. The specific areas of the samples correlate to a certain extent with their clay contents.

\section{Computing porosity from water adsorption}

Employing gas adsorption for computing porosity of materials is based on the fact that with contact angles of $\theta<90^{\circ}$ capillary condensation takes place, and the pores are spontaneously filled beginning from the smallest ones (Gregg and Sing 1982; Lowell 1979). If $\Theta$ $=0^{\circ}$ and the gas pressure is $\mathrm{p}$, all such capil- 

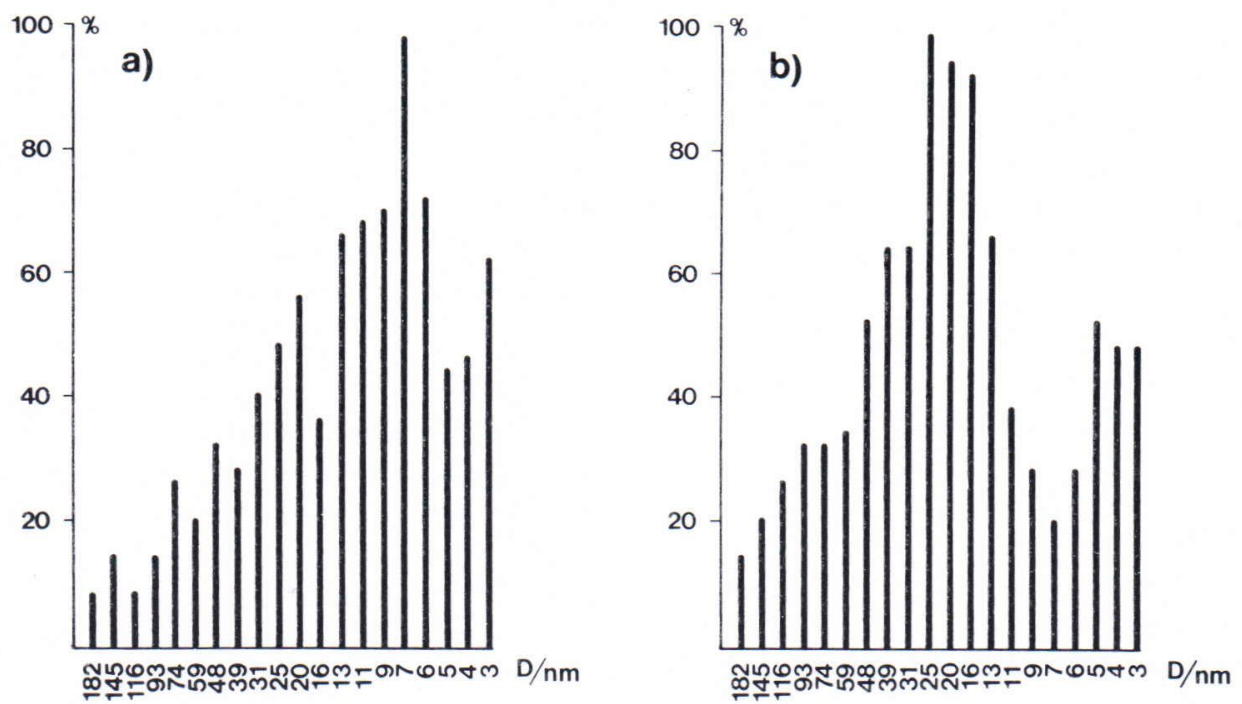

Fig. 4. Pore volume distributions found by water adsorption for samples a) and b) of Fig. 1. The pore volumes, 2.8 $\mathrm{cm}^{3} / \mathrm{kg}$ and $10.0 \mathrm{~cm}^{3} / \mathrm{kg}$ for samples a) and b), are only a few percent of the total pore volumes. On the other hand, the specific surface areas obtained from these porosity distributions, $1,040 \mathrm{~m}^{2} / \mathrm{kg}$ and $2,050 \mathrm{~m}^{2} / \mathrm{kg}$, are reasonable.

laries are filled which have diameters smaller than

$$
\mathrm{D}=-\frac{4 \gamma \mathrm{v}}{\mathrm{RT} \ln \left(\mathrm{p} / \mathrm{p}_{\mathrm{o}}\right)}
$$

where $\gamma$ is the surface tension of the liquid form of the gas and $v$ is its molar volume, $p_{o}$ is the vapor pressure of the liquid above a rlat surface, $\mathrm{T}$ is the absolute temperature, and $\mathrm{R}$ the gas constant.

A standard procedure for computing porosity from nitrogen adsorption (Gregg and Sing 1982; Lowell 1979) was modified in this study and applied to compute the porosity of 33 samples using the data of water adsorption (Nieminen and Kellomäki 1982 a). The necessary t-curves or statistical thickness of water films were obtained from a paper by Brunauer and his co-workers (Hagymassy et al. 1969). As we had only adsorption data, we used them instead of the usually employed desorption curves. For the use of adsorption results there are certain arguments in the literature (Hagymassy et al. 1972). In any case, a general view of mesoporosity is obtained regardless of the type of curve used.
The adsorption isotherms were drawn in a large scale and proper values were read from the curves for the calculations to obtain points evenly distributed along the $\lg (\mathrm{D})$ axis. The calculations were started at $\mathrm{a}\left(\mathrm{H}_{2} \mathrm{O}\right)=0.9895$ which corresponds to the pore diameter of $\mathrm{D}=$ $202 \mathrm{~nm}$. The analysis was extended to $\mathrm{a}\left(\mathrm{H}_{2} \mathrm{O}\right)$ $=0.350$ where $\mathrm{D}=2.9 \mathrm{~nm}$. Typical porosity diagrams are presented in Fig. 4. They cover the region of mesopores and small macropores which generally contains less than $5 \%$ of the total pore volume of the tills. Thus, the adsorption method misses most of the pores found with mercury porosimetry. Where the two methods overlap, they roughly agree. Usually less pore volume is found with adsorption, but in the case of samples with strong adsorption the opposite is true. Then water is evidently sorbed between the mineral layers and the presumptions of the capillary condensation model are violated.

The above computing procedure also gives specific surface areas. When the calculations are extended to the relative humidity of $43 \%$, pores approximately as small as with mercury 
porosimetry are reached. As seen in Table 1 the areas computed from water adsorption according to the capillary condensation model are between the areas found by mercury porosimetry and nitrogen adsorption. Considerably higher surface areas are obtained from water adsorption using the BET theory (Adamson 1976). It is evident that the adsorption of water on tills is partly chemical, and the observed monolayer capacity is too high.

\section{Conclusions}

Most of the pore volume of till samples is in macropores which cannot be detected or de- scribed by adsorption methods. Mercury porosimetry is an ideal tool for investigating such porosity. In addition to pore distributions, it gives quite reasonable values of specific surface areas. There is also evidence that using results of mercury porosimetry it is possible to predict the frost susceptibility of tills.

Acknowledgements. We express our gratitude to Ms. Tarja Salovaara and Mr. Arto Nieminen for technical assistance in the measurements, and to Ms. Kyllikki Kauppinen-Walin, translator, for checking the language of this paper.

Lowell, S., 1979. Introduction to powder surface area. Wiley, New York.

Nieminen, P. \& Kellomäki, A., 1982 a. Adsorption of water on the fine fractions of Finnish tills. Report 9. Tampere University of Technology, Department of Civil Engineering, Engineering geology (in Finnish with English summary).

Nieminen, P.\& Kellomäki, A., 1982 b. On the porosity of tills. Report 10. Tampere University of Technology, Department of Civil Engineering, Engineering geology (in Finnish with English summary).

Rootare, H. M. \& Prenzlow, C. F., 1967. Surface areas from mercury porosimeter measurements. J. Phys. Chem. 71, 2733-2736.

Manuscript received, January 27, 1984. vapor adsorption. III. Analysis of hydrated calcium silicates and Portland cements. J. Colloid and Interface Sci. 38, 20-34. 